Vol. 8(2), pp. 019-026, March, 2018

ISSN: 2276-7797 ICV: 5.98

Copyright (C2018, the copyright of this article is retained by the author(s)

DOI Link: http://doi.org/10.15580/GJMS.2018.2.031218044

http://gjournals.org/GJMS

\title{
Influence of Blunt Versus Sharp Expansion of Uterine Incision on Degree of Intraoperative Blood Loss at Caesarean Section
}

\author{
NONYE-ENYIDAH E ${ }^{1}$ ELI $S^{2}$
}

\author{
${ }^{1}$ Department of Obstetrics and Gynaecology, Braithwaite Memorial and Specialist Hospital \\ ${ }^{2}$ University of Port Harcourt Teaching Hospital
}

Article No.: 031218044

Type: Research

DOI: 10.15580/GJMS.2018.2.031218044

Submitted: 12/03/2018

Accepted: $23 / 03 / 2018$

Published: $31 / 03 / 2018$

${ }^{\star}$ Corresponding Author

Nonye-Enyidah E

E-mail: hernsi@yahoo.com

\section{Keywords:}

Caesarean section, blunt and sharp expansions, term pregnancies, estimated blood loss

\section{Background:}

Caesarean section is the most common major operation performed on women. Although caesarean section is much safe today due to improved techniques, anaesthesia, blood transfusion services and antibiotics, there are still major intra operative and post operative complications. Haemorrhage is one of the short term morbidities following caesarean section and may lead to maternal mortality.

Aim:

To determine which method of expansion of uterine incision at caesarean section (sharp and blunt) is associated with a reduction in blood loss.

Method:

A prospective randomized study conducted among booked antenatal women admitted in antenatal ward for elective caesarean section at the University of Port Harcourt Teaching Hospital (UPTH) over a period of nine months. The eligible 354 women (177 for each group) were counseled for participation in the study and informed consent obtained. A profoma was prepared for each participant. Blood loss estimation (EBL) was undertaken using both volumetric and gravimetric methods. The data was collected and analyzed using EPI INFO statistical software.

Results:

The mean age of women in blunt group was 31.6 years and 31.7 years in sharp group. All the women had formal education. The mean parity in blunt group was 1.4 and 1.5 in sharp group. The mean gestational age for both groups was 38.1 (SD 1.0) weeks. The mean EBL during the study period was 594.4 (SD 167.0) mls. The mean EBL for sharp group was 602.3 (SD 176.6) $\mathrm{mls}$ and 586.4 (SD 157.3) mls for blunt group. The mean EBL for women in blunt group who had uterine extension was 889.3 (SD 100.3) $\mathrm{mls}$ while that of sharp was 944.4 (SD190.9) mls.

Conclusion:

Caesarean section is a common obstetric operation and needs to be made as safe as possible. Although sharp expansion of the lower segment transverse uterine incision resulted in more blood loss, the difference is not statistically significant. The difference in blood loss following inadvertent extension between the two groups is statistically significant. There was no need for a blood transfusion. 


\section{INTRODUCTION:}

Caesarean section is the birth of a fetus through a surgical incision in the anterior abdominal wall and the uterine wall after the age of viability which is 28 weeks in Nigeria ${ }^{1,2}$. It may be performed when there is risk to the health of the mother or baby during the course of pregnancy or labour ${ }^{3}$. Caesarean section is one of the oldest operations in medical history with far reaching effect on the modern practice of obstetrics ${ }^{4}$. It was probably performed by traumatic accident or mainly post-mortem for several millennia in the ancient worlds of Mesopotamia, India, Egypt, Isreal and Rome ${ }^{5-7}$. The origin of caesarean section is unclear. It is believed to be derived from Latin verb Caedere meaning 'to cut'. It is also believed to have originated from the Roman custom, Lex Cesare in 715BC. The first documented case of successful caesarean section with the survival of the wife and baby was in 1500 by Jacob Nuffer ${ }^{5-8}$.

In the past virtually every woman who had caesarean section died. The reasons for the high mortality include surgery after a prolonged labour, absence of anaesthesia, sepsis and haemorrhage from poor surgical techniques. Lebas first advocated suturing the uterus in 1769 but the advice was rejected for a century. In 1876 Eduardo Porro (1842-1902) controlled haemorrhage and sepsis following caesarean section by performing total hysterectomy and bilateral salpingooophorectomy and suturing cervical stump to the anterior abdominal wall thereby reducing by half the mortality rate from its usual rate of $80-90 \%$. The lower segment uterine incision was popularized by Munro Kerr who performed his first lower segment caesarean section in 1911 and reported his result in the 1920s and 1930 s but acceptance by the British congress of Obstetrics and Gynaecology was in $1949^{7-9}$. Since then the role of caesarean section has been transformed from one carrying terrifying risks to the one which maternal death is extremely rare. This is attributed to introduction of anaesthesia, antibiotics, improvement in blood transfusion and improved surgical techniques ${ }^{7,8}$.

A variety of surgical techniques have emerged all with the intent of reducing morbidity and mortality associated with caesarean section ${ }^{7-13}$. These include modification of abdominal incisions which was initially made on either side of the linea alba, to midline vertical through the linea alba. More recently is the transverse suprapubic incision with its modifications like Pfannenstiel, Joel Cohen, Alfred Maylard, Mouchel, Pelosi and Cherney incisions. Other surgical techniques are closure and non-closure of peritoneum (visceral and parietal), insitu repair of uterine incision and uterine exteriorization, regional and general anaesthesia, cord traction and manual removal of placenta, blunt versus sharp expansion of uterine incision in the low transverse caesarean section ${ }^{14-25}$.

Intra-operative haemorrhage is one of leading causes of morbidity and mortality associated with caesarean section. Assessment of blood loss is difficult in the clinical obstetric setting because of dispersion of blood and blood mix with amniotic fluid ${ }^{16}$. Different figures varying from less than $500 \mathrm{mls}$ to more than $1000 \mathrm{mls}$ have been recorded as the estimated blood loss at caesarean section ${ }^{26-29}$.

Various techniques have also been described to measure blood loss during caesarean section. In most deliveries both in the delivery room and in the operating theatre, blood loss is estimated by virtual inspection which is inaccurate. The most practical method is the direct volumetric method, measuring the blood volume in basins, swabs and graduated bottle of a suctioning machine ${ }^{30}$. A gravimetric method used in assessment of blood loss has also been described 30 . It involves converting the increase in weight of blood-stained swabs and drapes into millimeters of blood on a millimeters per gramme basis ${ }^{30}$. Other methods are spectrophotometric and the radiometric technique using chromium 51 tagged erythrocytes ${ }^{30}$. Recently, the use of collecting bag and 'cholera beds' has been suggested to improve the estimation of postpartum bleeding ${ }^{30}$.

\section{OBJECTIVES:}

1. To determine the average amount of blood loss during caesarean section at University of PortHarcourt Teaching Hospital, south-south Nigeria.

2. To determine which method of expansion of uterine incision at caesarean section (sharp and blunt) is associated with a reduction in blood loss by comparing the estimated blood loss.

\section{METHODOLOGY:}

\section{Study Area:}

This study took place in the antenatal ward, labour ward theatre and postnatal ward of the University of Port Harcourt Teaching Hospital (UPTH) in Rivers state, Nigeria. UPTH is a tertiary health institution located in Port Harcourt, the capital of Rivers state. It serves as a referral centre for Rivers State with a population of about five million people, as well as the surrounding Bayelsa, Imo, Abia, Delta and Akwa lbom States. The hospital functions as a tertiary health facility although all pregnant and puerperal patients who present are attended to. The hospital has 512 bed spaces. Obstetric and Gynaecology department has 99 bed spaces with 56 obstetric beds. The labour ward has 2 admission rooms, 2 first stage rooms, 5 delivery suites and two theatres where all the caesarean sections in the department are performed. The delivery capacity of the unit is between 2,500 and 3,000 per annum with caesarean section rate of $32-36 \%$.

\section{Study Design:}


A prospective randomized study conducted among booked antenatal women admitted in antenatal ward for elective caesarean section at the University of PortHarcourt Teaching Hospital (UPTH) over a period of nine months. The eligible women were counseled to participate in the study. An informed consent was obtained after counseling. A proforma was prepared for each participant. Following study enrolment, the women were randomised to either group 1 (sharp expansion of the uterine incision) or group 2 (blunt expansion of the uterine incision) by chance following a randomization sequence as shown in appendix 1 . Equal number of women was chosen for each group i.e. 177 women for blunt group and another 177 women for sharp group. The assigned treatment is written on a pre-wrapped papers numbered up to 354 and sealed in a secure opaque envelop and the women asked to pick from the sealed envelope after counseling. The method of uterine expansion picked by each woman was used for her.

\section{Exclusion Criteria:}

These include women who decline to participate, those with antepartum haemorrhage, previous caesarean section, women undergoing emergency caesarean section, women with obvious multiple uterine fibroids, polyhydramnios and those with bleeding disorders

\section{Sample size:}

A minimum sample size of 354 women was used for the study after obtaining an informed consent.

\section{Method of estimation of blood loss used in the study:}

Both volumetric and gravimetric methods were used in this study. Blood loss estimation was undertaken by the operating surgeon, anaesthetists and the scrubbed nurse. This was done by measurement of blood in the container of a surgical suction machine which was put on as soon as the surgery started to mop off as much blood as possible with minimal staining of the drapes and operating table. The drapes and gowns were weighed together before and after the surgery and the difference in weight was the amount of blood staining them (1 gramme is equivalent to $1 \mathrm{ml}$ of blood). The swabs and laparotomy pads used during the surgery and after the surgery to clean the patient and the operating table were counted. The limitations here were the liquor amnii that mixed with the blood loss and the little amount of blood in the peritoneal cavity.

\section{Data Analysis:}

The data collected was fed into EPI INFO statistical software and presented in percentages, means and standard deviations. Chi-square tests were used to compare the groups as appropriate for statistical significance. $P$ value of $<0.05$ was assumed to be statistically significant.

\section{Study limitations:}

During the study, blood loss at caesarean section was mixed with liquor amnii making the estimation of blood loss slightly less precise. There were individual surgeon's variations in terms of skills in minimizing blood loss at surgery such as in expansion of the uterine incision.

\section{Ethical consideration:}

In designing this study, the following ethical issues were put into consideration. The purpose of the study was explained to all the eligible participants. They were assured that neither of the groups they were assigned to would constitute any danger to their management. They were assured of the confidentiality of the information obtained from them. The participants were also informed of their freedom to refuse or withdraw from the study at any point without prejudice to their usually expected standard of care. Thereafter, the informed consent form was signed by each participant. Ethical approval for this study was obtained from the hospital ethical review board. 


\section{RESULTS:}

Table 1: SOCIO-DEMOGRAPHIC CHARACTERISTICS OF PARTURIENTS

\begin{tabular}{|c|c|c|c|c|}
\hline Characteristics & Sharp N= 177 & $\%$ & Blunt $\mathrm{N}=177$ & $\%$ \\
\hline \multicolumn{5}{|l|}{ Age Group } \\
\hline$<20$ & 1 & 0.6 & 1 & 0.6 \\
\hline $20-24$ & 11 & 6.2 & 11 & 6.2 \\
\hline $25-29$ & 37 & 20.9 & 38 & 21.5 \\
\hline $30-34$ & 80 & 45.2 & 82 & 46.3 \\
\hline$\geq 35$ & 48 & 27.1 & 45 & 25.4 \\
\hline \multicolumn{5}{|l|}{$\begin{array}{l}\text { Educational } \\
\text { Level }\end{array}$} \\
\hline None & 0 & 0 & 0 & 0 \\
\hline Primary & 6 & 3.4 & 4 & 2.3 \\
\hline Secondary & 52 & 29.4 & 46 & 26.0 \\
\hline Tertiary & 119 & 67.2 & 127 & 71.8 \\
\hline \multicolumn{5}{|l|}{ Occupation } \\
\hline Civil Servant & 42 & 23.7 & 39 & 22.0 \\
\hline Trader & 42 & 23.7 & 43 & 24.3 \\
\hline Professional & 9 & 5.1 & 8 & 4.5 \\
\hline Public Servant & 21 & 11.8 & 20 & 11.3 \\
\hline Student & 15 & 8.5 & 20 & 11.3 \\
\hline Housewife & 48 & 27.1 & 47 & 26.6 \\
\hline \multicolumn{5}{|l|}{ Parity } \\
\hline 0 & 61 & 34.5 & 64 & 36.2 \\
\hline $1-2$ & 76 & 42.9 & 74 & 41.8 \\
\hline $3-4$ & 35 & 19.8 & 30 & 17.0 \\
\hline$\geq 5$ & 5 & 2.8 & 9 & 5.0 \\
\hline \multicolumn{5}{|l|}{ Marital Status } \\
\hline Married & 176 & 99.4 & 175 & 98.9 \\
\hline Single & 1 & 0.6 & 2 & 1.1 \\
\hline Widowed & 0 & 0 & 0 & 0 \\
\hline \multicolumn{5}{|l|}{ Tribe } \\
\hline Ibo & 60 & 33.9 & 70 & 39.5 \\
\hline ljaw & 33 & 18.6 & 22 & 12.4 \\
\hline Efik & 15 & 8.5 & 10 & 5.6 \\
\hline Ikwerre & 23 & 13.0 & 31 & 17.5 \\
\hline Yoruba & 12 & 6.8 & 10 & 5.6 \\
\hline Hausa & 6 & 3.4 & 9 & 5.1 \\
\hline Ogoni & 12 & 6.8 & 8 & 4.5 \\
\hline Urhobo & 7 & 4.0 & 12 & 6.8 \\
\hline Others & 9 & 5.1 & 5 & 2.8 \\
\hline
\end{tabular}


Table 2: ESTIMATED BLOOD LOSS OF PARTURIENTS

\begin{tabular}{|c|c|c|c|c|c|}
\hline $\begin{array}{l}\text { Estimated } \\
\text { Loss (m/s) }\end{array}$ & Blood & Sharp $N=177$ & $\%$ & Blunt $\mathrm{N}=177$ & $\%$ \\
\hline $200-300$ & & 4 & 2.3 & 4 & 2.3 \\
\hline $301-400$ & & 21 & 11.9 & 22 & 12.4 \\
\hline $401-500$ & & 53 & 29.9 & 57 & 32.2 \\
\hline $501-600$ & & 37 & 20.9 & 39 & 22.0 \\
\hline $601-700$ & & 26 & 14.7 & 26 & 14.7 \\
\hline $701-800$ & & 22 & 12.4 & 19 & 10.7 \\
\hline $801-900$ & & 7 & 3.9 & 4 & 2.3 \\
\hline $901-1000$ & & 3 & 1.7 & 4 & 2.3 \\
\hline$>1000$ & & 4 & 2.3 & 2 & 1.2 \\
\hline
\end{tabular}

The demographic characteristics of the patients in both groups are illustrated in table 1.

\section{Gestational age at caesarean section (C/S):}

The mean gestational age at $\mathrm{C} / \mathrm{S}$ for both groups was 38.1 (SD 1.0) weeks. The $p$ value is 0.870 which is not statistically significant.

\section{Pre-operative packed cell volume (PCV):}

The mean pre-operative pcv for the women in sharp group was 33\% (SD2.1) while those in blunt group had mean pcv of $33 \%$ (SD2.2). The difference is not statistically significant, $\mathrm{p}$ value $=0.941$.

\section{Post operative packed cell volume (pcv):}

The mean post-operative pcv for sharp group was $30.0 \%$ (SD 2.2) and $30.1 \%$ (SD 2.2) for blunt group. The difference is not statistically significant, $p$ value $=0.778$.

\section{Level of surgeon:}

One hundred and seventy two (97.2\%) caesarean sections in the sharp group were done by senior registrars while $5(2.8 \%)$ were done by consultants. One hundred and fifty six $(88.1 \%) \mathrm{c} / \mathrm{s}$ in the blunt group were done by senior registrars and $21(11.9 \%)$ by consultants.

\section{Intra-operative complications:}

Fourteen women (7.9\%) in the blunt group had extension of the primary uterine incisions. Of the fourteen women, 2 had extension upwards but not to the broad ligament, 2 had downward extension involving the cervix while the rest were about $1-2 \mathrm{~cm}$ extension of the primary incision. For the sharp group, 18 women had extension of the primary uterine incision. Of these women, 3 had cervical extension and another 2 had upward extension falling short of broad ligament involvement. The rest of the women had about 1-2 cm extension of the primary incision.

\section{Estimated blood loss (EBL):}

The mean estimated blood loss during the study period was 594.4 (SD167.0) mls. The estimated blood loss in the two groups is shown in table 2. The mean EBL in the sharp group was 602.3 (SD176.6) mls while that of blunt was 586.4 (SD157.3) mls. The difference is not statistically significant, $p$ value $=0.374$. For the sharp group, 33 women (18.6\%) lost less than $500 \mathrm{mls}$ of blood, $138(78.0 \%)$ lost between 500 and 999mls and 6 (3.4\%) lost at least $1000 \mathrm{mls}$ of blood.

Thirty five women (19.8\%) in the blunt group lost less than $500 \mathrm{mls}$ of blood, $136(76.8 \%)$ lost between 500 and $999 \mathrm{mls}$ while $6(3.4 \%)$ lost $\geq 1000 \mathrm{mls}$ of blood.

\section{Duration of surgery:}

The mean duration of operation in the blunt group was 54.2 (SD 13.0) minutes while that of sharp was 57.1 (SD 43.0) minutes.

\section{DISCUSSION}

For the study to have a valid result between the surgical techniques used and relate these to blood loss, it was necessary to ensure that reasons for obstetric haemorrhage were similar between the studied groups. This is why risk factors for obstetric haemorrhage were excluded in the study. In addition, the same surgical techniques and anaesthesia were used for all the women apart from the studied techniques i.e. blunt versus sharp expansion of uterine incision.

In this study, equal number of women in each group, $8(4.5 \%)$ were anaemic prior to surgery. The difference in mean pre-operative pcv of the women in both groups is not statistically significant. Pregnant women admitted in antenatal ward for caesarean section should be in the best possible condition because their ability to withstand blood loss at the time of surgery depends on the preoperative level of packed cell volume, blood volume, volume of blood lost and associated disease state ${ }^{21}$. Prior to the surgery, the cause of the anaemia was supposed to have been investigated and the anaemia corrected during the antenatal visits. 
Blood loss at the time of operative delivery was assessed by the surgeon, anaesthetist and the scrubbed nurse by measuring blood loss in the suction container, counting the number of surgical swabs used during surgery and weighing the surgical gowns and drapes before and after surgery and the difference in the weight is equivalent to the amount of blood in them (1 gramme $=1 \mathrm{mls}$ ). It has been shown that the estimation of blood loss at the time of surgery using this method is reasonably accurate and reflects actual blood loss as long as the calculations are done meticulously ${ }^{16}$. The only limitation to this is that blood mixes with liquor during caesarean section and is difficult to separate.

The mean estimated blood loss (EBL) during the study period was 594.4 (SD 167.0) mls. This is comparable to the mean EBL of $592 \mathrm{mls}$ noted in a similar study ${ }^{27}$. The mean EBL was more in the sharp group compared to the blunt group though the difference was not statistically significant. This is in keeping with a similar study done in $1994{ }^{15}$. Equal number of women in each group lost at least $1000 \mathrm{mls}$ of blood. All the women who lost at least $850 \mathrm{mls}$ of blood in both groups had uterine extension of the incision. The mean EBL for women in blunt group who had uterine extension was 889.3 (SD100.3) mls while that of sharp was 944.4 (SD190.9) mls. The difference in the mean blood loss for the women with the uterine extension in both groups is statistically significant, $p$ value $=0.048$. None of the women in this study was transfused despite that some of them lost about $1200 \mathrm{mls}$ of blood. This could be attributed to the fact that these women had high pcv to withstand the blood lost at surgery. The excellent compensatory mechanisms of pregnant women enable most of them to survive extensive haemorrhages without blood transfusion and recover a normal blood volume within a relatively short time following caesarean section 27.

The increased blood loss in sharp expansion of uterine incision could be as a result of myometrial ooze, traumatised vasculature or secondary to a greater forward extension of the distal incision. The reported advantage of sharp expansion is the precise expansion of the uterine incision thereby protecting the uterine artery and parametrial veins ${ }^{16}$. The advantages of blunt technique are speed and reduced bleeding from the myometrial edges ${ }^{16}$. This was seen in this study where more blood loss occurred in the sharp group and the mean surgery duration was less with the blunt group. The disadvantage of blunt expansion of uterine incision is the lack of control which may cause damage laterally to major blood vessels.

The mean pcv change for both groups was not statistically significant, $p$ value is 0.121 . The American college of Obstetricians and Gynaecologists has defined post partum haemorrhage as a change of $10 \%$ in the haematocrit between admission and post partum period or need for a red cell transfusion. None of the women in the study groups had a negative change in the pcv more than $10 \%$ between the pre-operative pcv and that obtained 48 hours after surgery. Therefore there was no need for blood transfusion. Also the women were haemodynamically stable intra-operatively and postoperatively and none had severe anaemia.

The mean hospital stay following surgeries in both groups was the same. The reason for some of the women staying longer than five days in the hospital was because of wound infection, hypertensive diseases in pregnancy and gestational diabetes mellitus. This is not unexpected because the wound infection had to be treated and the blood pressure with glycaemic control had to be optimal before discharging the women home.

\section{CONCLUSION:}

Sharp expansion of lower segment transverse uterine incision at caesarean section resulted in more blood loss and longer surgery duration than the blunt method though the difference is not statistically significant. The difference in blood loss following inadvertent extension between the two groups is statistically significant with more of the extension seen with sharp group. There was no need for blood transfusion and the change in packed cell volume is not statistically significant in both groups. Therefore uterine extension following sharp expansion of uterine incision causes more blood loss and the need for blood transfusion.

\section{RECOMMENDATION:}

Caesarean section is a common obstetric operation and needs to be made as safe as possible. Booked women for elective caesarean section should not be anaemic prior to the surgery because anaemia will worsen postoperatively with its consequences. In view of the more mean estimated blood loss, significant blood loss following inadvertent uterine extension and longer surgery duration seen in sharp group, blunt expansion of uterine incision should be encouraged in order to reduce morbidity and mortality associated with blood loss at caesarean section.

\section{STUDY LIMITATIONS:}

During the study, blood loss at caesarean section was mixed with liquor amnii making the estimation of blood loss slightly less precise. There were individual surgeon's variations in terms of skills in minimizing blood loss at surgery such as in expansion of the uterine incision.

\section{ETHICAL CONSIDERATION:}

In designing this study, the following ethical issues were put into consideration. The purpose of the study was explained to all the eligible participants. They were assured that neither of the groups they were assigned to 
would constitute any danger to their management. They were assured of the confidentiality of the information obtained from them. The participants were also informed of their freedom to refuse or withdraw from the study at any point without prejudice to their usually expected standard of care. Thereafter, the informed consent form was signed by each participant. Ethical approval for this study was obtained from the hospital ethical review board.

\section{REFERENCES:}

1. Ebeigbe PN, llesanmi AO. Caesarean section. In: Okpere E. (Ed). Clinical Obstetrics. University of Benin Press, Nigeria, 2003; 404-413.

2. Jaiyesimi RAK, Ojo OE. Caesarean section. In: Okonofua F, Odunsi K (Eds). Contemporary obstetrics and gynaecology for developing countries. Women's Health and Action Research Centre, Nigeria, 2003; 592-619.

3. Muthir JT, Daru PH, Ujah IAO. Elective caesarean section at the Jos University Teaching Hospital. Tropical Journal of Obstetrics and Gynaecology, 2005; 22 (1): 39-41.

4. Okonta PI, Otoide VO, Okogberin SA. Caesarean section at University of Benin Teaching Hospital revisited. Tropical Journal of Obstetrics and Gynaecology, 2003; 20(1): 63-66.

5. Boley JP. The history of caesarean section. Journal of Canadian Medical Association, 1991; 145(4): 31922.

6. Lurie S, Glezerman M. The history of caesarean section technique. American Journal of Obstetrics and Gynaecology, 2003; 189 (6): 1803-1806.

7. Uzoigwe SA, Jeremiah I. Developments in caesarean section techniques: A review. Nigerian Journal of Medicine, 2006; 15(1): 24-29.

8. Baskett TF, Calder AA, Arulkumaran S. Caesarean section. In: Baskett TF, Calder AA, Arulkumaran S (Eds). Munro Kerr's Operative Obstetrics. 11 $11^{\text {th }}$ Edition. Saunders Elsevier, London, 2007; 151-166.

9. Garriguez HJ. The improved caesarean section. American Journal of Obstetrics and Gynaecology, 1983; 16: 33.

10. Ezechi OC, Nwokoro CA, Kalu BKE, Njokanma FO, Okeke GCE. Caesarean Morbidity and Mortality in a Private Hospital in Lagos, Nigeria. Tropical Journal of Obstetrics and Gynaecology, 2002; 19(2): 97100.

11. Kerr JMM. The technique of caesarean section with special reference to the lower uterine segment incision. American Journal of Obstetrics and Gynaecology, 1926; 12: 729-734.

12. Hauth JC, Owen J, Davis RO. Transverse uterine incision closure. One versus two layers. American Journal of Obstetrics and Gynaecology, 1992; 167: 1108-1111.

13. Tucker JM, Hauth JC, Hodgkins $P$ et al. Trial of labour after one or two layer closure of a low transverse uterine incision. American Journal of Obstetrics and Gynaecology, 1993; 168: 545-561.

14. Chapman SJ, Owen J, Hauth JC. One versus two layer closure of a low transverse caesarean section: the next pregnancy. American Journal of Obstetrics and Gynaecology, 1997; 89(1): 16-18.

15. Rodriguez Al, Portei KB, O'Brien WF. Blunt versus sharp expansion of the uterine incision in low segment transverse caesarean section. American Journal of Obstetrics and Gynaecology, 1994; 171:1022-1025.

16. Magann EF, Chauhan SP, Bufkin L, Field K, Roberts WE, Martin JN Jr. Intraoperative haemorrhage by blunt versus sharp expansion of the uterine incision at caesarean delivery; a randomized clinical trial. British Journal of Obstetrics and Gynaecology, 2002; 109(4): 448-452.

17. Orion O, Luzuy F, Beguin F. Non closure of the visceral and parietal peritoneum at caesarean section: a randomized controlled trial. British Journal of Obstetrics and Gynaecology, 1996; 106: 690-694.

18. Stark M, Finkel AR. Comparison between JoelCohen and Pfannenstiel incisions in caesarean section. European Journal of Obstetrics and Gynaecology, 1994; 53: 121-122.

19. Hofmeyr J, Novikova N, Mathai M, Shah A. Techniques for caesarean section. American Journal of Obstetrics and Gynaecology, 2009; 201: 431.

20. Anorlu R, Maholwana B, Hofmeyr G. Methods of delivering the placenta at caesarean section. Cochrane Database systematic review, 2008; CD004737.

21. Bujold E, Goyet M, Marcoux S et al. The role of uterine closure on the risk of uterine rupture. Gynaecology. 2010; 116: 43.

22. Xu LL, Chau AMT, Zuschmann A. Blunt versus sharp uterine expansion of lower segment caesarean section delivery: a systematic review with meta-analysis. American Journal of Obstetrics and Gynaecology. 2013; 208(62): 1-8.

23. Jayasundara PMCS, Rajapakse RNG. Complications of blunt versus sharp expansion of the uterine incision in the lower segment caesarean section. A randomized controlled trial. Sri Lanka Journal of Obstetrics and Gynaecology. 2016; 37(4): 60-64.

24. Saad AF, Rahman M, Constantine MM, Saade GR. Blunt versus sharp uterine incision expansion during low transverse caesarean delivery: a meta-analysis. American Journal of Obstetrics and Gynaecology, 2014; 211(6): 684: 1-11.

25. Cheong $Y$, Premkumar G, Metwally $M$ et al. To close or not to close? A systematic review and a meta-analysis of peritoneal non-closure and adhesion formation after caesarean section. European Journal of Obstetrics, Gynaecology and Reproductive Biology, 2009; 147:3.

26. Beazley JM, Caesarean section. In: Turnbull A, Chamberlain G (Eds). Obstetrics. Livingstone, Edinburgh, 1989; 857-865. 
27. Khan FA, Khan M, Ali A, Chohan U. Estimation of blood loss during caesarean section audit. Journal of Parkistan Medical Association. 2006; 56: 572; 1-8.

28. Morgan Jr GE, Mikhail MS, Murray MJ. Fluid management and transfusion. In: Strauss $M$, Lebowitz $\mathrm{H}$, Boyle PJ (Eds). Clinical anaesthesiology, $4^{\text {th }}$ Edition. Mc GrawHill companies USA. 2006; 690-707.
29. American college of Obstetricians and Gynaecologists educational bulletin. Postpartum haemorrhage. International Journal of Gynaecology and obstetrics, 1998; 61(1): 79-86.

30. Walsh CA, Manias T, Brockelsby J. Relationship between haemoglobin change and estimated blood loss after delivery. British Journal of Obstetrics and Gynaecology, 2007; 114: 1447-1448.

Cite this Article: Nonye-Enyidah E, Eli S (2018). Influence of Blunt Versus Sharp Expansion of Uterine Incision on Degree of Intraoperative Blood Loss at Caesarean Section. Greener Journal of Educational Research, 8(2): 019-026, http://doi.org/10.15580/GJMS.2018.2.031218044. 